\title{
Editorial: Impure Snow and Ice in Remote Areas: Arctic, Antarctica and High Mountains
}

\author{
Jing Ming ${ }^{1 *}$, Khanghyun Lee ${ }^{2}$, Feiteng Wang ${ }^{3}$, Tong Zhang ${ }^{4}$ and Helle Astrid Kjær ${ }^{5}$ \\ ${ }^{1}$ Beacon Science \& Consulting, Adelaide, SA, Australia, ${ }^{2}$ Korea Polar Research Institute, Incheon, South Korea, ${ }^{3}$ State Key \\ Laboratory of Cryospheric Sciences, Chinese Academy of Sciences, Lanzhou, China, ${ }^{4}$ Beijing Normal University (previously at \\ Los Alamos Faculty of Geographical Science, National Laboratory, Los Alamos, United States), Beijing, China, ${ }^{5}$ Physics for Ice, \\ Climate and Earth, Niels Bohr Institute, University of Copenhagen, Copenhagen, Denmark
}

Keywords: snow, ice, impurities, remote areas, Arctic, Antarctica, high mountains

\section{Editorial on the Research Topic}

Impure Snow and Ice in Remote Areas: Arctic, Antarctica and High Mountains

Emissions of pollutants are transported to some of Earth's most remote areas. Increasingly intensified human activities into the industrial era, including industries, agriculture, transportation, and tourism continue to enhance pollutant depositions onto the surface. Snow and ice at these remote places are tainted with pollutants and are the carriers of such impurities. This topic issue, "Impure Snow and Ice in Remote Areas: Arctic, Antarctica and High Mountains," hosted by Frontiers in Earth Science, presents ten important papers to demonstrate the kinds of pollutants deposited as well as how, and where these pollutants get deposited and their impacts on the cryosphere.

The Arctic, home to snow and ice, is one of the most sensitive areas to climate change and a natural reflection of the environmental impacts from human activities. Matoba et al. found insoluble particles on the surface and in the deeper layers of the Qaanaaq Glacier, Greenland. The insolubleparticle concentration in the glacier ice at intermediate sites was approximately ten times larger than at low sites on this glacier. The resurfacing of the insoluble particles in ice due to ablation, and their coexistence in surface snow, enhanced the surface absorption of solar radiation and favoured the surface melting at the higher area of the glacier, an important climate feedback of such pollutants. Anthropogenic and natural metal and metalloid elements were found deposited in the snow of Svalbard (Koziol et al. and Spolaor et al.) via long-range transports. The on-site snow sampling in the Finish Arctic and the lab modelling work revealed a median black carbon (BC) concentration of 21-57 $\mu \mathrm{g} \mathrm{kg}^{-1}$ depending on the seasons deposited in the snow during 2009-2013.

In the mid-latitudes, the High Asian Mountains host a vast area of mountainous glaciers as the vital water resources to the livelihood of billions of people. These mountainous glaciers are rich in dust, $\mathrm{BC}$, and debris in the surface snow and beneath ice. These impurities contribute to the surface absorption of solar radiation and hence to the melting of glaciers. On Urumqi Glacier No. 1, there were more than $300 \mathrm{~g} \mathrm{~m}^{-2}$ of insoluble particles or dust covering the glacier on average, of which approximately $10 \%$ were organic matter. These particles largely darkened the glacier surface by reducing its albedo from 0.62 to 0.32 in summer (Yue et al.). The average concentration of BC mixed in the insoluble particles in snow reached as high as $\sim 600 \mu \mathrm{g} \mathrm{kg}^{-1}$, ten times more than that in the Arctic, and may reduce the surface albedo by 13-23\% (Zhang et al.). A more eastern glacier, Yushugou Glacier No. 6, also preserved heavily dusty snow as Urumqi Glacier No. 1, and $\mathrm{Ca}^{2+}$ and $\mathrm{SO}_{4}{ }^{2-}$ dominated the chemistry in the soluble components of the snow samples (Liu et al.). In the Hunza Valley of Karakoram, the supra-glacial debris showed an upward expansion during 1990-2019, suggesting the glaciers here would be more extensively covered by the heat-absorbed debris (Xie et al.). 
There is evidence that the impurities also influence the snow albedo in Antarctica. However, the particle emissions from the biomass burning in the Southern Hemisphere swept across the peripheral snow-ice covered area only occasionally. The reconstruction of biomass burning history relies largely on deep ice cores, and the Chinese Taishan Station in East Antarctica showed stable glaciology and ideal meteorology for a super-deep ice core drilling (Tang et al.). The ice-core explorations here will provide an essential background to evaluate future climate and environmental changes in Antarctica.

\section{AUTHOR CONTRIBUTIONS}

All authors listed have made a substantial, direct, and intellectual contribution to the work and approved it for publication.
Conflict of Interest: Beacon Science and Consulting (ABN 28737731 238) is an academic consulting service providing relevant service to clients registered with Australian Securities and Investments Commission. Author JM is the founder and also the executive of this service.

The remaining authors declare that the research was conducted in the absence of any commercial or financial relationships that could be construed as a potential conflict of interest.

Publisher's Note: All claims expressed in this article are solely those of the authors and do not necessarily represent those of their affiliated organizations, or those of the publisher, the editors and the reviewers. Any product that may be evaluated in this article, or claim that may be made by its manufacturer, is not guaranteed or endorsed by the publisher.

Copyright (c) 2022 Ming, Lee, Wang, Zhang and Kjor. This is an open-access article distributed under the terms of the Creative Commons Attribution License (CC BY). The use, distribution or reproduction in other forums is permitted, provided the original author(s) and the copyright owner(s) are credited and that the original publication in this journal is cited, in accordance with accepted academic practice. No use, distribution or reproduction is permitted which does not comply with these terms. 